\title{
Comparing three body mass index classification systems to assess overweight and obesity in children and adolescents
}

\author{
Ines Gonzalez-Casanova, ${ }^{1}$ Olga L. Sarmiento, ${ }^{2}$ Julie A. Gazmararian, ${ }^{3}$ \\ Solveig A. Cunningham, ${ }^{4}$ Reynaldo Martorell, ${ }^{4}$ Michael Pratt, ${ }^{4}$ \\ and Aryeh D. Stein ${ }^{4}$
}

Suggested citation

Gonzalez-Casanova I, Sarmiento OL, Gazmararian JA, Cunningham SA, Martorell R, Pratt M, et al. Comparing three body mass index classification systems to assess overweight and obesity in children and adolescents. Rev Panam Salud Publica. 2013;33(5):349-55.

ABSTRACT Objective. To compare the International Obesity Task Force (IOTF) 2005, Centers for Disease Control and Prevention (CDC) 2000, and World Health Organization (WHO) 2007 body mass index (BMI) classification systems in terms of prevalence estimation and association with demographic factors.

Methods. The 18265 children and adolescents ages 5 to 18 years ( mean $=11.2$ years, standard deviation $=3.9$ years) in the nationally representative Colombian National Nutrition Survey of 2005 were classified as overweight or obese according to IOTF, CDC, and WHO criteria. Prevalence estimates were compared according to each system and associations with age, sex, socioeconomic status, and population density were tested.

Results. Prevalence estimates of combined overweight and obesity differed by system (males: $\mathrm{IOTF}=8.5 \%, \mathrm{CDC}=10.8 \%, \mathrm{WHO}=14.1 \%$; females: $\mathrm{IOTF}=14.6 \%$, $C D C=13.8 \%, W H O=17.1 \% ; \mathrm{P}<0.001)$. The association between combined overweight and obesity and age and sex varied by system. The odds of having overweight and obesity in children (5 to 10 years) compared with adolescents (11 to 18 years) were: IOTF, odds ratio $(O R)=0.87$ and $95 \%$ confidence interval $(C I)=0.77-0.98 ; C D C, O R=1.27$ and $C I=1.14-1.42 ; W H O, O R=1.21$ and $C I=1.08-1.35$. The values for females compared with males were: $I O T F, O R=1.84$ and $C I=1.6-2.10 ; C D C, O R=1.33$ and $C I=1.17-1.51 ; W H O$, $O R=1.25$ and $C I=1.12-1.41$.

Conclusions. There is a lack of consistency among the three main international systems in assessing overweight and obesity in children and adolescents. Appreciably different estimates of prevalence and associations with age and sex are obtained depending on which system is used. Future studies should assess how well each system reflects valid measures of body composition.

Key words Adolescent; body mass index; child; overweight; obesity; World Health Organization; Colombia; Latin America.

1 Graduate Division of Biological and Biomedical Sciences, Emory University, Atlanta, Georgia 30322, United States of America. Send correspondence to: Ines Gonzalez-Casanova, igonza2@emory.edu

2 Facultad de Medicina, Universidad de los Andes, Bogotá, Colombia.
Department of Epidemiology, Rollins School of Public Health, Emory University, Atlanta, Georgia 30322, United States of America.

4 Hubert Department of Global Health, Rollins School of Public Health, Emory University, Atlanta, Georgia 30322, United States of America.
Overweight and obesity in children and adolescents represent a burden to individuals and populations worldwide due to associations between obesity and many adverse cardiometabolic and psy- 
chosocial problems (1). Concern about increased childhood obesity worldwide has led to implementation of a wide range of programs and policies (2). Interventions are often designed and targeted based on prevalence estimates and inferred associations with sociodemographic factors obtained from survey data $(1,2)$. Typically, the prevalence of overweight and obesity is estimated by categorizing individuals according to their body mass index (BMI) $\left(\mathrm{kg} / \mathrm{m}^{2}\right)$; the accuracy of this approach relies on the relation of this measure to the percentage of body fat (3).

The use of BMI is a widely accepted and affordable method to infer body composition in children and adults (3). However, in children (5 to 10 years) and adolescents (11 to 18 years), in whom sex and age play an important role in body composition (4), there is not a clear consensus on which BMI classification system should be used to diagnose overweight and obesity $(5,6)$. Three classification systems are frequently used internationally to assess obesity: the International Obesity Task Force (IOTF) criteria, developed in 2005 by a group of IOTF experts, who extrapolated the adult BMI cutoff points for overweight $\left(25 \mathrm{~kg} / \mathrm{m}^{2}\right)$ and obesity $\left(30 \mathrm{~kg} / \mathrm{m}^{2}\right)$ to data sets from six countries (6); the United States Centers for Disease Control and Prevention (CDC) growth charts issued in 2000, a revision of the National Center for Health Statistics (NCHS) 1977 growth reference that incorporated data from five national surveys conducted between 1963 and 1994 in the United States of America and used statistical smoothing techniques (7); and the World Health Organization (WHO) criteria, which were developed by a WHO expert committee in 2007 using the 1977 NCHS growth reference from 5 to 19 years, supplemented with data from the WHO Child Growth Standards for children ages 5 years and younger (to facilitate the transition at age 5) (5). The IOTF has been used increasingly outside the United States, but some evidence suggests this classification system has lower sensitivity than the WHO, CDC, and local classification systems for diagnosing overweight and obesity in children and adolescents compared with percentage of body fat as the gold standard (8-10). Some of the barriers to develop and validate BMI classification systems in older children and adolescents include the difficulty in finding a healthy reference population and the lack of long-term follow-up studies with information on health out- comes in diverse populations $(5,6)$. Previous studies have reported that prevalence estimates of overweight and obesity in children and adolescents differ according to the IOTF, CDC, and WHO classification systems (11-13). Generally, IOTF prevalence estimates are lower than other local and international references, and WHO estimates are the highest. However, these studies examined limited age ranges of children, usually in samples that were not nationally representative, and did not describe differences in estimation according to demographic characteristics. To address this gap, the objective of this study is to estimate the prevalence of overweight and obesity using the $\mathrm{WHO}, \mathrm{CDC}$, and IOTF classification systems; to assess their concordance; and to determine whether they suggest different associations with age, sex, location of residence (rural or urban), and wealth in a nationally representative survey from Colombia.

\section{MATERIALS AND METHODS}

\section{Sample}

This study used data from the Encuesta Nacional de la Situación Nutricional en Colombia (ENSIN) 2005 (14), a nationally representative survey with a stratified cluster design, which is a subsample of the Colombian Demographic and Health Survey (DHS) 2005. The original DHS sample included 37211 households stratified by clusters (household segments), out of which ENSIN sampled 17740 households (Figure 1). The response rates for ENSIN ranged between $88 \%$ and $99 \%$ depending on measurement and region. All children and adolescents 5 to 18 years old with available information on age, sex, height, and weight were included. Participants with implausible values for weight, height, and BMI [defined as more than \pm 5 standard deviations (SD) from the mean of the WHO reference population]; those with missing information on area of residence or the wealth index; and those who were pregnant were excluded.

\section{BMI classification and outcome variables}

BMI was calculated for all participants, who then were classified as overweight, obese, or neither overweight nor obese according to the IOTF, CDC, and WHO cutoffs. IOTF cutoffs are an extrapolation of the adult BMI cutoff points for overweight $\left(25 \mathrm{~kg} / \mathrm{m}^{2}\right)$ and obesity $\left(30 \mathrm{~kg} / \mathrm{m}^{2}\right)$. The CDC system defines overweight as a BMI above the 85th percentile of the reference population and obesity as a BMI above the 95th percentile. The WHO system defines overweight as a $\mathrm{BMI}>1 \mathrm{SD}$ and obesity as a BMI $>2$ SD from the mean of the WHO reference population (5).

\section{Sociodemographic characteristics}

Age was computed from the date of birth and date of the interview, rounded to the nearest integer year; for the logistic regression models, it was categorized as children 5 to 10 years old and adolescents 11 to 18 years old. IOTF provides year-specific cutoffs, while CDC and WHO provide month-specific cutoffs.

Sex was identified as male or female.

A wealth index (WI) was developed for DHS that assesses the presence in the household of a range of assets, such as television, type of flooring, water supply, refrigerator, electricity, radio, television, and a domestic servant (15). The WI was generated as the first component of a principal components analysis. Individuals were classified into five categories based on the distribution of the national household population (I = poorest, $\mathrm{V}=$ wealthiest) (15).

FIGURE 1. Description of sample for this study, from Colombian Demographic and Health Survey to final sample of children and adolescents, 2005

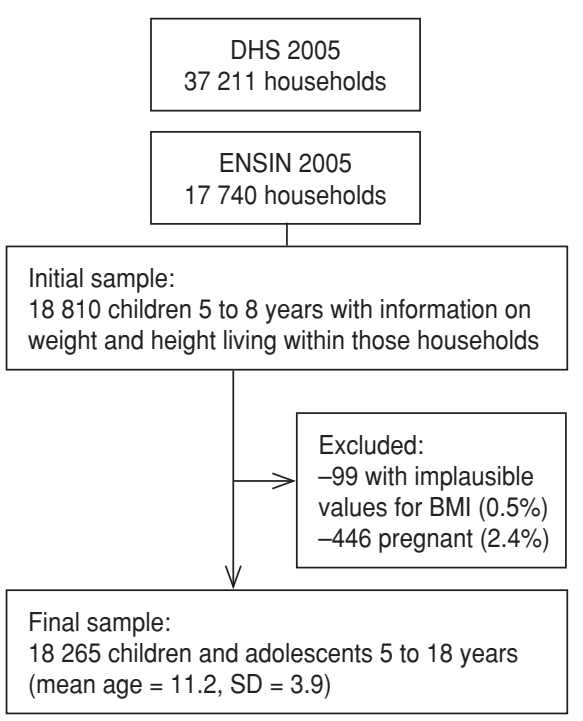

DHS: Colombian Demographic and Health Surveys, ENSIN: Encuesta Nacional de la Situación Nutricional en Colombia, BMI: body mass index, SD: standard deviation. 
FIGURE 2. Body mass index (BMI) by age in 5- to 18-year-old children, Colombia, 2005

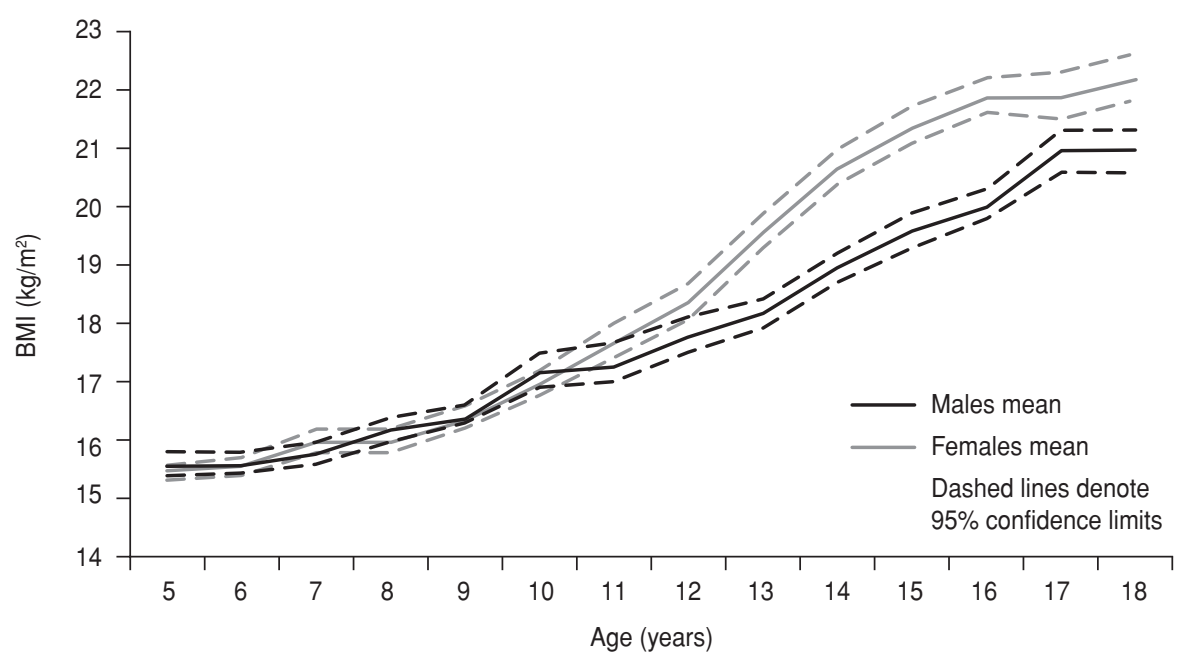

Source: Colombian National Nutrition Survey 2005.

Settlements with 10000 or fewer inhabitants were classified as rural areas and those with a population of 10001 or more were classified as urban.

\section{Statistical analysis}

The prevalence of overweight and obesity was estimated using IOTF, CDC, and WHO classification systems. All subjects with a BMI above the obesity cutoff points of each classification system were classified as obese, and all subjects with a BMI above the cutoff point for overweight were considered as combined overweight and obese. The distributions of overweight and obesity according to WHO and CDC were compared with IOTF (the most widely used classification system in international settings) using chi-square tests. To avoid increasing the probability of a type 2 error due to multiple comparisons, the CDC system was not compared with the WHO system.

Logistic regression analysis was conducted to estimate odds ratios (ORs) and $95 \%$ confidence intervals (CIs) of overweight, obesity, and combined overweight and obesity by each of the three classification systems (WHO, CDC, IOTF) according to age, sex, area of residence, and WI quintile (all the variables were modeled simultaneously). The study tested for all possible two-way multiplicative interactions $(n=8)$ by age, sex, socioeconomic status, and population density, using $P<0.05$ as a thresh- old. Analyses were conducted using SAS software, version 9.2 of the SAS System for Windows. The study used SAS callable SUDAAN 2010 (Research Triangle Institute, Research Triangle Park, North Carolina, United States) to account for the complex survey design and maintain the representativeness of the sample.

\section{RESULTS}

The study excluded 99 individuals with implausible values for weight, height, or BMI; 3 individuals who lacked information on area of residence; and 446 girls who were pregnant. The final sample included 18265 children and adolescents, 8817 boys, and 9448 girls.

\section{BMI by age and sex}

BMI was normally distributed. The mean BMI increased with age (Figure 2); it was similar in boys and girls up to age 12, after which the patterns diverged, with a greater BMI increase among girls.

\section{Prevalence of overweight and obesity by age and sex using three classification systems}

The prevalence of combined overweight and obesity was highest according to the WHO classification in males and females at all ages (Figure 3); the CDC classification yielded the lowest prevalence in males, and the IOTF classification yielded the lowest prevalence in females. Overall, the CDC and WHO distributions of overweight and obesity differed significantly from the IOTF distribution $(P<0.05)$ (Table 1$)$.

FIGURE 3. Prevalence of combined overweight and obesity in children 5 to 18 years old, estimated using World Health Organization (WHO), Centers for Disease Control and Prevention (CDC), and International Obesity Task Force (IOTF) classification methods by age and sex, Colombia, 2005
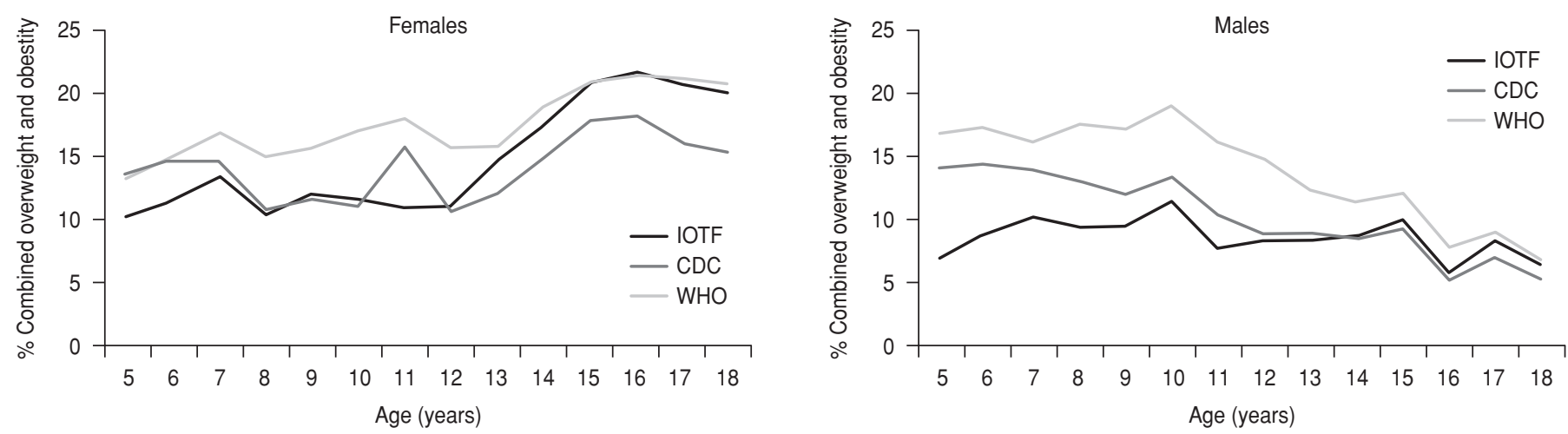

Source: Colombian National Nutrition Survey 2005. 
TABLE 1. Prevalence of overweight and obesity by sex in 5- to 18-year-old children, Colombia, 2005

\begin{tabular}{|c|c|c|c|c|c|c|c|c|c|c|c|c|}
\hline \multirow{2}{*}{ Characteristic } & \multicolumn{6}{|c|}{ Male $(n=8817)^{\mathrm{a}}$} & \multicolumn{6}{|c|}{ Female $(n=9448)^{\mathrm{a}}$} \\
\hline & \multicolumn{2}{|c|}{$\begin{array}{c}\text { International } \\
\text { Obesity Task Force }\end{array}$} & \multicolumn{2}{|c|}{$\begin{array}{l}\text { Centers for } \\
\text { Disease Control } \\
\text { and Prevention }\end{array}$} & \multicolumn{2}{|c|}{$\begin{array}{l}\text { World Health } \\
\text { Organization }\end{array}$} & \multicolumn{2}{|c|}{$\begin{array}{c}\text { International } \\
\text { Obesity Task Force }\end{array}$} & \multicolumn{2}{|c|}{$\begin{array}{l}\text { Centers for } \\
\text { Disease Control } \\
\text { and Prevention }\end{array}$} & \multicolumn{2}{|c|}{$\begin{array}{l}\text { World Health } \\
\text { Organization }\end{array}$} \\
\hline $\begin{array}{l}\text { Neither overweight } \\
\text { nor obese }\end{array}$ & 91.5 & 0.5 & 89.2 & 0.5 & 85.9 & 0.6 & 85.4 & 0.6 & 86.2 & 0.6 & 82.9 & 0.6 \\
\hline $\begin{array}{l}\text { Overweight } \\
\text { (excluding obese) }\end{array}$ & 6.7 & 0.4 & 7.3 & 0.5 & 10.3 & 0.5 & 12.5 & 0.6 & 10.6 & 0.5 & 13.9 & 0.6 \\
\hline
\end{tabular}

Source: Colombian National Nutrition Survey 2005.

a Distribution of overweight and obesity differs by International Obesity Task Force (6), Centers for Disease Control and Prevention (7), and World Health Organization (5) classification systems within $\operatorname{sex}(P<0.05)$.

b SE: standard error.

TABLE 2. Odds ratios (OR) and 95\% confidence intervals $(\mathrm{Cl})$ of association between overweight and obesity and different demographics, Colombia, $2005^{\mathrm{a}}$

\begin{tabular}{|c|c|c|c|c|c|c|}
\hline \multirow[b]{2}{*}{ Demographic } & \multicolumn{2}{|c|}{ International Obesity Task Force } & \multicolumn{2}{|c|}{$\begin{array}{c}\text { Centers for } \\
\text { Disease Control and Prevention }\end{array}$} & \multicolumn{2}{|c|}{ World Health Organization } \\
\hline & OR & $95 \% \mathrm{Cl}$ & OR & $95 \% \mathrm{Cl}$ & OR & $95 \% \mathrm{Cl}$ \\
\hline \multicolumn{7}{|l|}{ Obesity } \\
\hline Female & 1.22 & $0.88-1.68$ & 0.94 & $0.74-1.18$ & 0.87 & $0.69-1.09$ \\
\hline $5-10$ years & $1.52^{b}$ & $1.12-2.08$ & $1.96^{b}$ & $1.54-2.51$ & $1.80^{b}$ & $1.41-2.31$ \\
\hline \multicolumn{7}{|l|}{ Wealth index categoryc } \\
\hline II & 1.64 & $0.78-3.46$ & $1.81^{b}$ & $1.01-3.27$ & 1.71 & $0.95-3.08$ \\
\hline III & 3.45 & $1.59-7.52$ & 3.66 & $2.09-6.40$ & 3.46 & $1.98-6.02$ \\
\hline IV & 3.74 & $1.67-8.39$ & 5.06 & $2.74-9.34$ & 5.10 & $2.76-9.43$ \\
\hline V & 5.43 & $2.44-12.10$ & 6.08 & $3.31-11.16$ & 5.79 & $3.18-10.57$ \\
\hline Urban & 1.21 & $0.70-2.10$ & 0.97 & $0.64-1.48$ & 1.06 & $0.69-1.63$ \\
\hline \multicolumn{7}{|c|}{ Combined overweight and obesity } \\
\hline Female & $1.84^{\mathrm{b}}$ & $1.61-2.10$ & $1.33^{b, d}$ & $1.17-1.51$ & $1.25^{b, d}$ & $1.12-1.41$ \\
\hline $5-10$ years & $0.87^{b}$ & $0.77-0.98$ & $1.27^{\mathrm{b}, \mathrm{d}}$ & $1.14-1.42$ & $1.21^{b, d}$ & $1.08-1.35$ \\
\hline \multicolumn{7}{|l|}{ Wealth index categoryc } \\
\hline II & 1.23 & $0.94-1.61$ & $1.33^{b}$ & $1.17-1.51$ & $1.30^{\mathrm{b}}$ & $1.02-1.64$ \\
\hline III & $1.83^{b}$ & $1.41-2.39$ & $1.88^{b}$ & $1.44-2.45$ & $1.76^{b}$ & $1.38-2.26$ \\
\hline IV & $2.28^{b}$ & $1.71-3.04$ & $2.48^{b}$ & $1.88-3.26$ & $2.21^{b}$ & $1.70-2.88$ \\
\hline V & $3.09^{b}$ & $2.29-4.16$ & $3.11^{b}$ & $2.32-4.19$ & $2.81^{b}$ & $2.13-3.70$ \\
\hline Urban & 0.98 & $0.80-1.21$ & 0.99 & $0.81-1.22$ & 1.01 & $0.84-1.21$ \\
\hline
\end{tabular}

a Model includes sex, age categorical, wealth index, and population density, with male, 11-18 years, wealth index I, and rural as the reference.

b Statistically significant $(P<0.05)$.

${ }^{c}$ Categories I to $\mathrm{V}$ are from lowest to highest socioeconomic status.

d OR estimate significantly different from International Obesity Task Force estimate $(P<0.05)$.

Overweight and obesity demographic patterns according to IOTF, CDC, and WHO classification systems

Overweight and obesity pattern according to IOTF. According to the IOTF classification, girls had higher odds than boys of combined overweight and obesity $(\mathrm{OR}=1.84, \mathrm{CI}=1.61-2.10)$, but there was no association between sex and obesity alone. The likelihood of younger children ( 5 to 10 years) being obese was 1.52 times that of adolescents. There was a significant interaction $(P<0.05)$ between age and sex for combined overweight and obesity: 5- to 10-year-old females were less likely to be overweight or obese
$(\mathrm{OR}=0.69, \mathrm{CI}=0.59-0.81)$ than $11-$ to 18-year-old females, while 5- to 10-yearold males were 1.28 times more likely to be overweight or obese than older boys $(\mathrm{CI}=1.04-1.58)$. Both obesity and combined overweight and obesity were elevated in WI quintiles III, IV, and V compared with WI quintiles I and II (Table 2). For combined overweight and obesity, there was a significant interaction between WI and sex $(P<0.05)$ : the positive association of overweight with WI was stronger in males than in females. Population density (urban versus rural) was not significantly associated with overweight, obesity, or combined overweight and obesity after controlling for WI (Table 2).
Comparing overweight and obesity according to CDC and IOTF systems. The magnitude of the CDC estimate of the association between being female and overweight and obesity $(\mathrm{OR}=1.33$, $\mathrm{CI}=1.17-1.51)$ was smaller than the IOTF estimate $(\mathrm{OR}=1.84, \mathrm{CI}=1.61-2.10)$. The association of combined overweight and obesity with age was opposite to the one found with IOTF (OR of children versus adolescents: $\mathrm{CDC}=1.27, \mathrm{CI}=1.14-1.42$ versus $\mathrm{IOFT}=0.87, \mathrm{CI}=0.77-0.97)$. Similar to IOTF, the interactions between age and sex for combined overweight and obesity were significant $(P<0.05)$. The positive associations of obesity and combined overweight and obesity with WI 
were broadly similar between the CDC system and the IOTF system (Table 2).

\section{Comparing overweight and obesity ac-} cording to the WHO and IOTF systems. With the WHO classification system, there was a positive association between combined overweight and obesity and being female $(\mathrm{OR}=1.25, \mathrm{CI}=1.12-1.41)$; the magnitude of this estimate was significantly different from the IOTF estimate $(P<0.05)$ (Table 2$)$. The association between combined overweight and obesity and age was also opposite to the one found with IOTF (and consistent with CDC). Similar to IOTF, there was no association between obesity and sex. The interaction between age and sex for combined overweight and obesity was significant $(P<0.05)$. The positive association between obesity and combined overweight and obesity and WI was consistent with the IOTF system (Table 2).

\section{DISCUSSION}

The study found that prevalence estimates of overweight and obesity in Colombian 5- to 18-year-old children and adolescents differed significantly across classification systems. These differences are consistent with other studies that reported that the WHO system generally yields the highest prevalence estimates, while the IOTF system yields the lowest $(8,11-13)$. It is critical to consider the effect of the choice of classification system on the prevalence estimate when comparing surveillance information from different settings or studies describing secular trends. The three classification systems for ages 5 to 18 years were developed with different objectives: IOTF included surveys conducted in six countries (including those used to develop NCHS 1977) with the objective of obtaining an international reference (6); CDC used five U.S. national nutrition and health surveys conducted between 1963 and 1994 with the objective of developing a reference for the U.S. population (7); and WHO was developed using only NCHS 1977 to have a "nonobese sample with expected heights" and to obtain an equivalent of the healthy population used to develop the growth charts for children less than 5 years old (5). These different objectives and sources of reference populations partially explain the differences in prevalence estimation. WHO yields the highest prevalence esti- mate of overweight and obesity because its reference population is intended to be a nonobese sample, whereas CDC and IOTF are derived using more recent data in which the BMI distribution of the reference populations is already shifted toward the right because of the recent increase in child and adolescent BMI.

This study used these three classification systems to estimate associations between basic sociodemographic characteristics and overweight and obesity. The study found that the patterns of association differed depending on the classification system, especially in relation to age and sex. For example, according to IOTF but not according to WHO and CDC, there was an inverse association between age and overweight. The most relevant difference found was for combined overweight and obesity where, according to the IOTF classification system, there was an inverse association between child age and overweight or obesity, while according to the WHO and CDC systems this association was positive. It is possible that because IOTF is the only system that uses age in integer years and not in months (6), this system misses small age-related variations in BMI, which may be more relevant in children ( 5 to 10 years old).

There was greater concordance between the estimates generated with the three systems when we examined obesity alone rather than combined with overweight. This better agreement is encouraging because childhood obesity is more strongly associated with negative health outcomes than is overweight (16). Apart from minor differences among the IOTF and the CDC and WHO classification methods in the significance of association with WI, no major disagreement among the three systems in the estimates of association with WI or population density was found after controlling for age and sex. In this sense, age and sex are different types of predictors because they were considered by all three classification systems when the cutoff points were defined $(5,6,12)$. Thus, the variations in prevalence estimation are highly sex and age specific. This potentially explains the differences in association found for combined overweight and obesity.

The results of this study outline the importance of considering the differences in BMI and population estimates depending on the classification system selected; it is especially relevant for researchers, organizations, and policy makers interested in using survey data to study associations of different sociodemographic factors with overweight and obesity in children and adolescents. It is particularly important to consider age and sex as covariates in all studies of childhood and adolescent overweight and obesity not only because they are two of the most common confounders but also because they can account for part of the error introduced by the BMI classification systems. The use of waist circumference has recently been suggested as a reliable and feasible alternative to BMI for assessing total body fat in this age group (17). However, there are similar problems with the interpretation of that measurement.

The main goals of assessing childhood obesity at the population level are to identify the prevalence, trends, and determinants of this condition; to design appropriate public health interventions to prevent it; and to identify populations at risk of suffering the health consequences of obesity. Hence, in order to advance the field of obesity research and prevention, it is necessary to establish the potential of the available BMI classification systems to reflect percentage of fat and to predict adverse health consequences and develop valid and reliable systems to assess overweight and obesity in children and adolescents around the world. In the meantime, when studying associations of overweight and obesity with demographic characteristics in school children and adolescents, we recommend considering the objectives and limitations of the three systems in order to select the most appropriate for each study population. IOTF was the first recommendation designed specifically to be used in international populations; it used surveys from six countries from 1963 to 1993, and the extrapolation of the adult BMI cutoff points facilitates the transition from assessing children's to adults' BMIs. However, it has low sensitivity diagnosing overweight and obesity compared with the other methods and does not provide month-specific cutoff points. The CDC system is frequently used internationally; however, it was designed using only information from the United States with the objective of documenting obesity trends in that country. The WHO classification is the only system designed using data from 
before the obesity epidemic; hence, it might be the most appropriate for countries where the prevalence of childhood obesity is still relatively low, such as Colombia. BMI is a convenient and feasible tool to screen for overweight and obesity in children and adolescents. However, further studies are needed to improve the interpretation of this measure and to recommend a unique international BMI classification system that adequately reflects the percentage of fat and the risk of negative health outcomes.

This study has some limitations. First, there is no information on body composition, including percent body fat, or reliable information on health outcomes (such as incidence of adult obesity, diabetes, and cardiovascular disease and other morbidities or early death) that could be used to determine which classification system performs best as a screening tool. Hence, only differences in prevalence can be described. Also, in this cross-sectional study, one cannot assess the incidence of obesity or follow the sample to assess BMI over time. These limitations add to the difficulties of assessing body composition in children and adolescents, where variations due to puberty and sexual maturation complicate the creation of universal cutoffs to classify overweight and obesity (18-20). Still, the study included a large, nationally representative sample of Colombian children and adolescents and used three current and widely recommended BMI classification systems. This approach made it possible to demonstrate the differences in estimates of prevalence and in the inference about associations with demographic factors among the three systems most frequently used to assess overweight and obesity internationally.

Funding. Support for I.G.-C.'s graduate studies at Emory University was provided by the Consejo Nacional de Ciencia y Tecnología of Mexico and by the Coca-Cola Company via an unrestricted training grant to the CDC Foundation. The Demographic and Health Survey of Colombia 2005 was funded by the U.S. Agency for International Development, the United Nations Population Fund, the Colombian Institute of Family Welfare, and Colombia's Ministry of Social Protection.

\section{Conflict of interest. None.}

\section{REFERENCES}

1. Lobstein T, Baur L, Uauy R. Obesity in children and young people: a crisis in public health. Obes Rev. 2004;5(Suppl 1):4-104.

2. Whitlock EP, Williams SB, Gold R, Smith PR, Shipman SA. Screening and interventions for childhood overweight: a summary of evidence for the US Preventive Services Task Force. Pediatrics. 2005;116(1):e125-44.

3. Dietz WH, Bellizzi MC. Introduction: the use of body mass index to assess obesity in children. Am J Clin Nutr. 1999;70(1):123S-5S.

4. Guo SS, Chumlea WC, Roche AF, Siervogel RM. Age- and maturity-related changes in body composition during adolescence into adulthood: the Fels Longitudinal Study. Int J Obes Relat Metab Disord. 1997;21(12):1167-75.

5. de Onis M, Onyango AW, Borghi E, Siyam A, Nishida C, Siekmann J. Development of a WHO growth reference for school-aged children and adolescents. Bull World Health Organ. 2007;85(9):660-7.

6. Cole T, Bellizzi M, Flegal K, Dietz W. Establishing a standard definition for child overweight and obesity worldwide: international survey. BMJ. 2000;320(7244):1240-3.

7. Kuczmarski RJ, Ogden CL, Guo SS, GrummerStrawn LM, Flegal KM, Mei Z, et al. 2000 CDC growth charts for the United States: methods and development. Vital Health Stat 11. 2002;246:1-190.

8. Fu WP, Lee HC, Ng CJ, Tay YK, Kau CY, Seow CJ, et al. Screening for childhood obe- sity: international vs population-specific definitions. Which is more appropriate? Int J Obes Relat Metab Disord. 2003;27(9):1121-6.

9. Neovius M, Linné YM, Barkeling BS, Rossner SO. Sensitivity and specificity of classification systems for fatness in adolescents. Am J Clin Nutr. 2004;80(3):597-603.

10. Zimmermann MB, Gübeli C, Püntener C, Molinari L. Detection of overweight and obesity in a national sample of 6-12-y-old Swiss children: accuracy and validity of reference values for body mass index from the US Centers for Disease Control and Prevention and the International Obesity Task Force. Am J Clin Nutr. 2004;79(5):838-43.

11. Twells LK, Newhook LA. Obesity prevalence estimates in a Canadian regional population of preschool children using variant growth references. BMC Pediatr. 2011;11(1):21.

12. Kovalskys I, Rausch Herscovici C, De Gregorio MJ. Nutritional status of schoolaged children of Buenos Aires, Argentina: data using three references. J Public Health (Oxf). 2011;33(3):403-11.

13. Khang YH, Park MJ. Trends in obesity among Korean children using four different criteria. Int J Pediatr Obes. 2011;6(3-4):206-14.

14. Instituto Colombiano de Bienestar Familiar. Encuesta Nacional de la Situacion Nutricional en Colombia 2005. Bogotá: Instituto Colombiano de Bienestar Familiar; 2005.

15. Rutstein SO, Johnson K. The DHS wealth index. Calverton, Maryland: ORC Macro; 2004.
16. Dietz WH. Health consequences of obesity in youth: childhood predictors of adult disease. Pediatrics. 1998;101(3 Pt 2):518-25.

17. Cornier MA, Després JP, Davis N, Grossniklaus DA, Klein S, Lamarche B, et al. Assessing adiposity: a scientific statement from the American Heart Association. Circulation. 2011;124(18):1996-2019.

18. Himes JH, Park K, Styne D. Menarche and assessment of body mass index in adolescent girls. J Pediatr. 2009;155(3):393-7.

19. Okada T, Kuromori Y, Miyashita M, Yoshino Y, Iwata F, Hara M, et al. Assessment of individual changes in body fatness in boys during early pubertal period. Pediatr Int. 2005;47(5):495-7.

20. Tybor DJ, Lichtenstein AH, Dallal GE, Daniels SR, Must A. Independent effects of age-related changes in waist circumference and BMI $\mathrm{z}$ scores in predicting cardiovascular disease risk factors in a prospective cohort of adolescent females. Am J Clin Nutr. 2011;93(2):392-401.

Manuscript received on 23 July 2012. Revised version accepted for publication on 13 December 2012. 
RESUMEN Objetivo. Comparar los sistemas de clasificación de los índices de masa corporal (IMC) del Grupo de Trabajo Internacional sobre la Obesidad (IOTF) de 2005, de los Centros para el Control y la Prevención de Enfermedades (CDC) de 2000, y de la

Comparación de tres sistemas de clasificación de los índices de masa corporal para evaluar el sobrepeso y la obesidad en niños y adolescentes prevalencia y la asociación con factores demográficos.

Métodos. Los 18265 niños y adolescentes de ambos sexos y de edades comprendidas entre 5 y 18 años (media $=11$,2 años, desviación estándar $=3,9$ años) que participaron en la Encuesta Nacional de la Situación Nutricional en Colombia del 2005, representativa a escala nacional, fueron clasificados como afectados de sobrepeso $\mathrm{u}$ obesidad según los criterios del IOTF, los CDC y la OMS. Se compararon los cálculos de la prevalencia según cada sistema y se analizaron las asociaciones con la edad, el sexo, la situación socioeconómica y la densidad de población.

Resultados. Los cálculos de la prevalencia del sobrepeso y la obesidad combinados diferían según el sistema (varones: $\mathrm{IOTF}=8,5 \%, \mathrm{CDC}=10,8 \%, \mathrm{OMS}=14,1 \%$; mujeres: $\mathrm{IOTF}=14,6 \%, \mathrm{CDC}=13,8 \%, \mathrm{OMS}=17,1 \% ; P<0,001)$. La asociación entre el sobrepeso y la obesidad combinados y la edad y el sexo también variaban según el sistema de clasificación. Las probabilidades de tener sobrepeso y obesidad en los niños (de 5 a 10 años) en comparación con los adolescentes (de 11 a 18 años) fueron: IOTF, razón de posibilidades $(\mathrm{OR})=0,87$ e intervalo de confianza del 95\% (IC) 0,77-0,98; CDC, $\mathrm{OR}=1,27$ e IC 1,14-1,42; OMS, OR = 1,21 e IC 1,08-1,35. Los valores observados en las mujeres en comparación con los varones fueron: IOTF, OR = 1,84 e IC 1,6-2,10; CDC, $\mathrm{OR}=1,33$ e IC 1,17-1,51; OMS, OR = 1,25 e IC 1,12-1,41.

Conclusiones. Existe una falta de uniformidad entre los tres principales sistemas internacionales en la evaluación del sobrepeso y la obesidad en niños y adolescentes. Se obtienen cálculos apreciablemente diferentes de la prevalencia y de las asociaciones con la edad y el sexo según el sistema que se adopte. Los estudios futuros deben evaluar hasta qué punto cada sistema refleja adecuadamente mediciones válidas de la composición corporal.

Palabras clave Adolescente; índice de masa corporal; niño; sobrepeso; obesidad; Organización Mundial de la Salud; Colombia; América Latina. 